\title{
HELIUM BACKGROUND IN THE D-ZERO DETECTOR RELATED TO THE PHOTOMULTIPLIER TUBES
}

D-ZERO ENGINEERING NOTE \# 3823.130-EN-490

Approved :

Kurt Krempetz, PPD/ETT/DO Upgrade/Mechanical group leader

April 9, 1998

Author: Russ Rucinski

PPD/ETT/D-Zero Upgrade project

APPENDIX

April 8, 1999

Author: Jason Lambin

PPD/ETT/D-Zero Upgrade project 
Summary

\begin{tabular}{|c|c|c|c|}
\hline Source & Max. Continuous & Max. Discrete & $\begin{array}{l}\text { Effect on Tubes } \\
\text { During } 10 \text { year run }\end{array}$ \\
\hline Solenoid system & $\begin{array}{l}180 \mathrm{ppm} \text { Helium } \\
\text { [Away from tubes] }\end{array}$ & $\begin{array}{l}100 \% \text { Helium }<1 \mathrm{~min} . \\
\text { [Away from tubes] }\end{array}$ & None \\
\hline \multirow[t]{3}{*}{ VLPC system } & $\begin{array}{l}270 \mathrm{ppm} \text { Helium } \\
\text { [Away from tubes] }\end{array}$ & & None \\
\hline & $\begin{array}{l}10 \text { ppm Helium } \\
\text { [4 to } 6 \text { "B,C" layer tubes] }\end{array}$ & & None \\
\hline & & $\begin{array}{l}1.3 \% \text { He decaying to }<100 \\
\text { ppm in } 5 \text { min. } \\
\text { [By } 10 \text { to } 20 \text { "B" layer } \\
\text { tubes] }\end{array}$ & $\begin{array}{l}\text { None } \\
\text { Lifetime at } 1.3 \% \text { Is } 45 \text { days. } \\
\text { Expect } 1.3 \% \text { for total } 80 \\
\text { min. over } 10 \text { year run }\end{array}$ \\
\hline $\begin{array}{l}\text { Calorimeter cold } \\
\text { vaive actuation gas }\end{array}$ & Negligible probability & $\begin{array}{l}7 \% \text { He decaying to }<100 \\
\text { ppm in } 30 \text { minutes } \\
\text { [By } 2 \text { "A" layer tubes] }\end{array}$ & $\begin{array}{l}\text { None } \\
\text { Lifetime at } 7 \% \text { is } 8 \text { days. } \\
\text { Expect to actuate cold valve } \\
2 \text { to } 4 \text { times over } 10 \text { yr run. }\end{array}$ \\
\hline Tev Magnet & $\begin{array}{l}100 \text { to } 200 \mathrm{ppm} \text { Helium } \\
\text { [Away from tubes] }\end{array}$ & $\begin{array}{l}5 \% \text { He decaying to }<100 \\
\text { ppm in } 25 \text { minutes. } \\
\text { [Magnet rupture, } \\
\text { Envelopes D0 detector] }\end{array}$ & $\begin{array}{l}\text { None- Lifetime at } 5 \% \text { : } \\
\text { Borositicate tubes, } 11 \text { days } \\
\text { Quartz tubes, } 167 \text { minutes } \\
\text { Expect maybe } 1 \text { discrete } \\
\text { event during entire run. }\end{array}$ \\
\hline
\end{tabular}

Discussion and Background:

Helium is present in the earth's atmosphere at about 5 parts per million. (ref. Technology of liquid helium, NBS monograph 111). The D-Zero detector uses helium for the cryogenic cooling of its superconducting magnet and visible light photon counter (VLPC) electronics chips. In addition, the tevatron accelerator has superconducting magnets that use helium. Due to the possibility of leaks or releases of helium from these helium lines and components, the background helium level in the collision hall may exceed the natural level of $5 \mathrm{ppm}$. This engineering note will quantify the probability and level of helium background in the D-Zero detector.

The photomultiplier tubes used in the D-Zero detector are sensitive to an elevated helium atmosphere. This is due to the permeation rate of helium gas through the glass tube, into the vacuum space inside. It is very important for the helium atmosphere surrounding the photomultiplier tubes is known and controlled. If the level of helium in the vacuum tube reaches a level above $5 \mathrm{ppm}$, then the photomuliplier tube may no longer work as designed. The process is an irreversible one.

\section{Photomultiplier tube susceptibility}

The time for the helium level in the photo tube to reach a certain level by diffusion is given by ${ }^{1}$ :

Time $=-$ tau* $\left(1-\mathrm{P}_{\text {tube }} / \mathrm{P}_{\text {sumoundings }}\right) \quad$ where: $\operatorname{tau}=10^{10}$ seconds for Borosilicate glass

$=10^{9}$ seconds for UV glass

$=10^{8}$ seconds for Quartz glass

This information is shown in the Table 1

${ }^{1}$ E-mail communication from Rich Partridge, Brown University, referenced from Hamamatsu photomultiplier data book. Tau is representative, not exact as DO is not using Hamamatsu phoro tubes. 
Table 1. Time to reach $5 \mathrm{ppm}$ for a sustained exposure

\begin{tabular}{cccc} 
& & Exposure Time & \\
Sustained Helium & Quartz & UV glass & Borosilicate \\
\cline { 1 - 2 } & & & \\
\hline $5 \mathrm{ppm}$ & infinite & infinite & infinite \\
$10 \mathrm{ppm}$ & 2.2 years & 22 years & 200 years \\
$100 \mathrm{ppm}$ & 59 days & 1.6 years & 16 years \\
$0.1 \%$ & 6 days & 58 days & 1.6 years \\
$1 \%$ & 14 hours & 6 days & 58 days \\
$10 \%$ & 83 minutes & 14 hours & 6 days \\
$100 \%$ & 8.3 minutes & 83 minutes & 14 hours
\end{tabular}

Quartz photomultiplier tubes are going to be used for the luminosity monitors. They will be located between the central calorimeter and end calorimeters surrounding the beam pipe. Note that their location is at least 5 meters away from any helium source. From Table 1 it is seen that the quartz photomultiplier tubes can tolerate a high level of concentration for a short time. A sustained low level concentration of only $10 \mathrm{ppm}$ however, could cause a premature death of the tubes before the 5 to 7 year physics run is complete.

The muon trigger counters use Borosilicate photomultiplier tubes. These tubes are more widely distributed through out the DO detector. They are mounted on the "A", "B", and " $\mathrm{C}$ "layers of the proportional drift tube chambers. These tubes are more hardy and can tolerate a reasonable elevated helium background.

\section{Helium dispersion behavior}

A helium leak disperses into the surrounding air by diffusion and rises upward due to its lesser density. To better understand qualitatively what it happens, I can calculate some dimensioniess parameters. First, I assume the case of a discrete release of helium that mixes evenly with the surrounding air into a 1 meter diameter sphere. Assume the helium/air mix is $5 \%$ helium, $95 \%$ air.

The Grashoff number $(\mathrm{Gr})^{2}$ is the ratio of the buoyancy forces to viscous forces for the gas. It typically is calculated to understand free convection heat transfer. A warm or cold surface induces flow by changing the fluid density.

$\mathrm{Gr}=\mathrm{g}^{*}$ Beta*$^{*}(\mathrm{Ts}-\mathrm{Tinf})^{*} \mathrm{~L}^{\wedge} 3 / \mathrm{mu}^{\wedge} 2$ where: $\mathrm{g}=$ acc. Due to gravity, Beta=fluid expansion coeff., $\mathrm{Ts}=$ surface temp., Tinf=temp. far away, $\mathrm{L}=$ characteristic length, $\mathrm{mu}=$ viscosity

Beta $=(1 /$ RHO $) *($ RHOinf - RHO $) /($ Tinf $-\mathrm{T})$ where: RHOinf $=$ fluid densit $y$ far away, RHO=fluid density of air/helium mix, $\mathrm{T}=$ Avg., Fluid temp $=($ Ts + Tinf $) / 2$

Substituting the second equation into the first, the temperatures cancel out. By plugging in all the values, and using I meter for the characteristic length, $\mathrm{Gr}=4000$. The buoyancy force is huge compared to the viscous drag type forces on the fluid mix.

The Schmidt number $(\mathrm{Sc})$ provides a measure of the relative effectiveness of momentum and mass transport by diffusion in the velocity and concentration boundary layers. ${ }^{2}$ It is the ratio of viscous forces and mass diffusivities.

\footnotetext{
${ }^{2}$ Incropera and Dewitt, Fundamentals of heat and mass transfer, $2^{\text {nd }}$ ed., 1985.
} 
$\mathrm{Sc}=\mathrm{mu} \mathrm{D} \quad$ where: $\mathrm{mu}=$ viscosit $y, \mathrm{D}=$ binary diffusion coefficient

The Binary diffusion coefficient for helium in air is not given in reference 2. They are given for other gasses in air, including hydrogen, which is probably similar to helium in diffusion. All the binary diffusion coefficients are about the same order of magnitude, and guessing the value to be the same as hydrogen, $\mathrm{Sc}=0.5$. The viscous transport and diffusion transport are the same order of magnitude.

The ratio of the buoyancy force to mass diffusivities can obrained by multiplying the Grasshoff number by the Schmidt number. The resuit is $\mathrm{Gr} * \mathrm{Sc}=2000$. This shows that the buoyancy force dominates the way the helium moves away from the release sight. The buoyant transport is about a 2000 times larger influence than the diffusion transport of the helium. The helium will go straight up and make its way out of the collision hall.

One can also calculate that the 1 meter sphere of $5 \%$ helium and $95 \%$ air will have a net buoyancy force of 0.26 Newtons. Applying $a=F / M$, we find that the acceleration on the helium sphere is $0.48 \mathrm{~m} / \mathrm{s}^{\wedge} 2$. It takes about 2 seconds for the sphere to move upward 1 meter.

These caiculations give one the intuitive sense that the helium will rapidly rise vertically before it disperses outward horizontally. Trapped helium in inverted pockets could possibly occur, but shouldn't be a problem for the phototube installations.

\section{Sources of helium in the D-Zero detector:}

1. Liquid helium supply/returns for solenoid

2. Lead flow returns from solenoid

3. Relief valves from solenoid control dewar

4. Liquid helium supply/returns for VLPC detector

5. Cassette space gas helium volume

6. Calorimeter cold valve actuation gas

7. Tevatron magners and tunnel

Each of the above sources will be elaborated on below. Specifically, I will: a.) speculate method of the release, b.) describe the location, c.) quantify the potential and amount of a helium release, $d$.) calculate the helium concentration and duration of such a release. Quite a few assumptions are made to arrive at hard numbers. The volume around the leak is assumed to be ventilated at the rate of $1 / 4$ volume change per minute. This is the approximately the same ratio as the collision hall ventilation rate. Fans of $23,700 \mathrm{cfm}$ (A.HU-1 gives 19,200 cfm, EF-7 gives $4500 \mathrm{cfm}$ ) move air through the 100,000 cubic foot D0 detector. The volume change is assumed to be with fresh air with no elevated concentration of helium. This assumption is valid because the huge volume of the collision hall dilutes virtually all the helium leaks to a negligible level.

1.) Liquid helium supply/returns for solenoid: A reasonable method of a release from theses lines would be through a failed o-ring leak at the u-tube bayonet fitting, a leaking trapped volume relief, a leaking tube fitting from a pressure tap to transmitter line, valve packing leak etc. All these potential types of leaks occur at the control dewar location positioned outside the detector at an elevation about 12.5 feet above the beam line. There are no photo tubes mounted above the location. The nearest photo tubes are 2 to 3 feet to the north and west of the location. The likelihood of such a leak is say 25 items * (3E-6 failures/hr) $(8766 \mathrm{hrs} / \mathrm{yr})=0.7$ leaks per year. The total leak rate would be a maximum of 1 $\mathrm{cc} / \mathrm{sec}$ air $=0.005 \mathrm{scfm}$ helium. (Note that a leak detectable by snoop is $1 / 1000^{\text {th }}$ of this $=0.001 \mathrm{~atm}$ -

${ }^{2}$ Incropera and Dewitt, Fundamentais of heat and mass transfer, $2^{\text {nd }}$ ed., 1985. 
$\mathrm{cc} / \mathrm{sec}$ air). For the sake of a number, assume the helium is distributed through a spherical volume with 3 foot radius. The resultant helium background would be around $180 \mathrm{ppm}$. The concentration level should reduce as cubic function of the distance from the source. The duration of such a release could be for the whole run since the leak may not be noticed or discovered. Even though the probability is that one such leak would occur every year and a half, the total leak rate assumed is rather large and should account for any combination of multiple leaks that may occur during the run.

\section{0 ppm Helium \\ [Away from tubes]}

2. Lead flow returns from solenoid: The method and location of a leak from these items is similar to the solenoid supply lines above. The elevation of such a leak is a few feet higher, within 5 feet of the top of the detector. There are going to be 6 potential leak sites all enclosed in the lead flow purge box. The GN2 purge box would dilute any such leak by about 0.5 scfm purge/ 0.005 scfm helium $\Rightarrow 100$ before it's release out of the box. The elevated helium concentrations are 100 times less than those calculated for source number 1 . That is ( 5 ppm (natural background) $+6 \mathrm{ppm}=11 \mathrm{ppm}$ at 2 feet away and ( 5 ppm (natural background) +2 ppm- 7 ppm at 3 feet away.

\section{Negligible ppm}

[Away from tubes]

3. Relief valves from solenoid control dewar: The solenoid has relief val ves that protect the process lines and helium subcooler vessel. The cause of a relief discharge could be a quench or an operational upset. The location of the discharge and elevated helium almosphere is the control dewar location described in the previous cases. It's hard to estimate how often a release could happen, in the operational test of the magnet at Toshiba the relief valves did not come close to having to open from a forced quench of the magnet. For a rough guess, say it might occur 4 times a year. The rate of release is large $616 \mathrm{cfm}$ helium, for a short duration, say 5 seconds at most, for a release of about $50 \mathrm{scf}$ helium (equivalent to 2 liquid liters of helium). The local concentration would initially be high, approximately $100 \%$ up to 3 feet from the relief valve. Modeling the helium as a sphere, the sphere would rise above and away from the detector in a matter of seconds. Any such releases from the relief valves would be discrete short term exposures of helium to the tubes.

\section{$100 \%$ Hellum $<1$ min.}

[Away from tubes]

4. Liquid helium supply/retums for VLPC detector: These lines connect via u-tubes in the same area as the solenoid control dewar. There are 6 bayonets and 6 trapped volume relief valves at that location. The conservative failure rate of the bayonets and relief valves is about 0.3 failures per year. A leak rate of $0.005 \mathrm{scfm}$ helium is reasonable. The duration of such a leak would probably be for the duration of the run. The maximum local concentration at the end of 5 years above the bayonet feed can could be $(5 \mathrm{yrs})(0.3 / \mathrm{yr})(180 \mathrm{ppm})=270 \mathrm{ppm}$. This location is not in the area of any photo tubes.

\section{0 ppm Helium}

[Away from tubes]

The other leak sources are the stems of two control valves located in a valve box in the center-east section of the detector platform. These stems are bellow sealed and each have a failure rate of about $(1 \mathrm{E}-8 / \mathrm{hr})^{*}(8677 \mathrm{hrs} / \mathrm{yr})=1.7 \mathrm{E}-4$ per year. The valve box location is probably within 10 feet of a "B" or " $\mathrm{C}$ " layer photo tube. The failure rate is low enough that it can be neglected. If it did fail, the mixing and distances involved would probably cause a maximum helium concentration of about 80 ppm at the closest photo tube location. The helium concentration would probabi y dilute by the distance from the 
So photo tubes 20 feet away would see at most $10 \mathrm{ppm}$ above the normal atmospheric

$10 \mathrm{ppm}$ Helium
$[4$ to 6 "B,C" layer tubes]

gas helium volume: The cassette space volume is located in the center of the detector e cassette space is a stagnant volume that surrounds the cold end of each of the 102 VLPC

ch VLPC cassette has a gasket and silicone potting at the warm optical fiber/flex circuit 1 estimate the leak rate for a cassette bulkhead to be $1 \mathrm{E}-2 \mathrm{~atm}-\mathrm{cc} / \mathrm{sec}$ helium $=2 \mathrm{E}-5 \mathrm{cfm}$ iplied by the 100 cassettes, then the total seady state leak rate is going to be $0.002 \mathrm{cfm}$ rer the $1.5 \mathrm{ft} \times 12 \mathrm{ft}$ long surface area of the cryostats. The center section of the platform with fans at a rate of $2080 \mathrm{cfm}$ and has a volume of about $1600 \mathrm{cf}$. The raised helium from the cassette leaks is on the order of 1 or $2 \mathrm{ppm}$.

$$
\begin{aligned}
& \text { Negligible ppm } \\
& \text { [By } 10 \text { to } 20 \text { "B" layer tubes] }
\end{aligned}
$$

ig to he low pressure relief valves protecting the cassette space. These will refieve ated from a warm up of the cassette-space.-These retief vatves are going to have their nto the argon spill duct which is located not more than 10 feet away. The spill duct has tilation out of the detector area.

nge operation would al so release helium gas. A cassette change would occur 2 times per Jperational spares are included as a subset of the total 102 cassette installation. During ne probably would keep a positive helium supply to the cassette space to prevent back $\mathrm{r}$ an -noisture into the cassette space which could be cold. In between the actual ca: and blanking off the hole again, helium would escape out of the cassette slot

tes. I estimate $30 \mathrm{scf}$ of helium is released during this operation. The elevated helium the center section of the platform could be as high as $1.25 \%=12,500 \mathrm{ppm}$ helium for a tes. The concentration would then decrease exponentially thereafter.

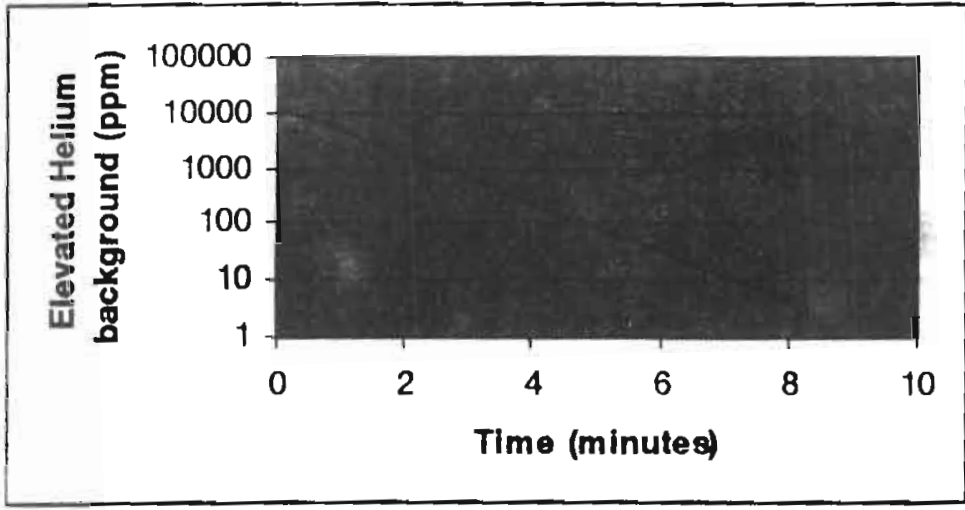

เski

$1.3 \%$ He decaying to $<100 \mathrm{ppm}$ in $5 \mathrm{~min}$.

[By 10 to 20 "B" layer tubes]

valve actuation gas: The cold valves are fed by $1 / 4$ " tubing lines that run from the SE comer of platform) up the cryobridge and to the tops of the three calorimeters. : most part is continuous with some joints. There are muon chambers and counters if thing run. The probability of a leak is around ( 10 joints $)(1 \mathrm{E}-8 / \mathrm{hr})(8766$

bin

Jpgrade project

pgrade project 
Table 1. Time to reach $5 \mathrm{ppm}$ for a sustained exposure

\begin{tabular}{cccc} 
& & Exposure Time & \\
Sustained Helium & Quartz & UV glass & Borosilicate \\
\hline$\frac{\text { Exposure }}{5 \mathrm{ppm}}$ & intinite & infinite & infinite \\
$10 \mathrm{ppm}$ & 2.2 years & 22 years & 200 years \\
$100 \mathrm{ppm}$ & 59 days & 1.6 years & 16 years \\
$0.1 \%$ & 6 days & 58 days & 1.6 years \\
$1 \%$ & 14 hours & 6 days & 58 days \\
$10 \%$ & 83 minutes & 14 hours & 6 days \\
$100 \%$ & 8.3 minutes & 83 minutes & 14 hours
\end{tabular}

Quartz photomultiplier tubes are going to be used for the luminosity monitors. They will be located between the central calorimeter and end calorimeters surrounding the beam pipe. Note that their location is at least 5 meters away from any helium source. From Table 1 it is seen that the quartz photomultiplier tubes can tolerate a high level of concentration for a shor time. A sustained low level concentration of only $10 \mathrm{ppm}$ however. could cause a premature death of the tubes before the 5 to 7 year physics run is - complete.

The muon trigger counters use Borosilicate photomultiplier tubes. These tubes are more widely distributed through out the DO detector. They are mounted on the "A", "B", and "C" layers of the proportional drift tube chambers. These tubes are more hardy and can tolerate a reasonable elevated helium background.

\section{Helium dispersion behavior}

A helium leak disperses into the surrounding air by diffusion and rises upward due to its lesser density. To tetter understand qualitatively what it happens, I can calculate some dimensionless parameters. First, I assume the case of a discrete release of helium that mixes evenly with the surrounding air into a I meter diameter sphere. Assume the helium/air mix is $5 \%$ helium, $95 \%$ air.

The Grashoff number $(\mathrm{Gr})^{2}$ is the ratio of the buoyancy forces to viscous forces for the gas. It typically is calculated to understand free convection heat transfer. A warm or cold surface induces flow by changing the fluid density.

$\mathrm{Gr}=\mathrm{g}^{*}$ Beta*$^{*}(\mathrm{Ts}-\mathrm{Tinf})^{*} \mathrm{~L}^{\wedge} 3 / \mathrm{mu}^{\wedge} 2$ where: $\mathrm{g}=$ acc. Due to gravity, Beta $=$ fluid expansion coeff., Ts=surface temp., Tinf=temp. far away, $\mathrm{L}=$ characteristic length, $\mathrm{mu}=$ viscosity

Beta $=(1 / \text { RHO })^{*}($ RHOinf - RHO $) /($ Tinf $-\mathrm{T})$ where: RHOinf $=$ fluid density far away, RHO=fluid density of air/helium mix, $\mathrm{T}=$ Avg., Fluid temp $=($ Ts + Tinf $) / 2$

Substituting the second equation into the first, the temperatures cancel out. By plugging in all the values, and using 1 meter for the characteristic length, $\mathrm{Gr}=4000$. The buoyancy force is huge compared to the viscous drag type forces on the fluid mix.

The Schmidt number $(\mathrm{Sc})$ provides a measure of the relative effectiveness of momentum and mass transport by diffusion in the velocity and concentration boundary layers. ${ }^{2}$ It is the ratio of viscous forces and mass diffusivities.

\footnotetext{
${ }^{2}$ Incropera and Dewitt, Fundamentais of heat and mass transfer, $2^{\text {nd }}$ ed., 1985.
} 
$\mathrm{Sc}=\mathrm{m} w \mathrm{D} \quad$ where: $m u=$ viscosity, $\mathrm{D}=$ binary diffusion coefficient

The Binary diffusion coefficient for helium in air is not given in reference 2. They are given for other gasses in air, including hydrogen, which is probably similar to helium in diffusion. All the binary diffusion coefficients are about the same order of magnitude, and guessing the value to he the same as hydrogen, $\mathrm{Sc}=0.5$. The viscous transport and diffusion transport are the same order of magnitude.

The ratio of the buoyancy force to mass diffusivities can obrained by multiplying the Grasshoff number by the Schmidt number. The result is $\mathrm{Gr}^{*} \mathrm{Sc}=2000$. This shows that the buoyancy force dominates the way the helium moves away from the release sight. The buoyant transport is about a 2000 times larger influence than the diffusion transport of the helium. The helium will go straight up and make its way out of the collision hall.

One can also calculate that the 1 meter sphere of $5 \%$ helium and $95 \%$ air will have a net buoyancy force of 0.26 Newtons. Applying a $=F / M$, we find that the acceleration on the helium sphere is $0.48 \mathrm{~m} / \mathrm{s}^{\wedge} 2$. It takes about 2 seconds for the sphere to move upward 1 meter.

These calculations give one the intuitive sense that the helium will rapidly rise vertically before it disperses outward horizontally. Trapped helium in inverted pockets could possibly occur, but shouldn't be a problem for the phototube instaltations.

\section{Sources of helium in the D-Zero detector:}

1. Liquid helium supply/retums for solenoid

2. Lead flow retums from solenoid

3. Relief valves from solenoid control dewar

4. Liquid helium supply/returns for VLPC detector

5. Cassette space gas helium volume

6. Calorimeter cold valve actuation gas

7. Tevatron magnets and tunnel

Each of the above sources will be elaborated on below. Specifically, I will: a.) speculate method of the release, $b$.) describe the location, c.) quantify the potential and amount of a helium release, $d$.) calculate the helium concentration and duration of such a release. Quite a few assumptions are made to arrive at hard numbers. The volume around the leak is assumed to be ventilated at the rate of $1 / 4$ vol ume change per minute. This is the approximately the same ratio as the collision hall ventilation rate. Fans of $23,700 \mathrm{~cm}$ (AHU-1 gives 19,200 cfm, EF-7 gives $4500 \mathrm{cfm}$ ) move air through the 100,000 cubic foot D0 detector. The volume change is assumed to be with fresh air with no elevated concentration of helium. This assumption is valid because the huge volume of the collision hall dilutes virtually all the helium leaks to a negligible level.

1.) Liquid helium supply/retums for solenoid: A reasonable method of a release from theses lines would he through a failed o-ring leak at the u-tuhe bayonet fitting, a leaking trapped volume relief, a leaking tube fitting from a pressure tap to transmitter line, valve packing leak etc. All these potential types of leaks cccur at the control dewar location positioned outside the detector at an elevation about 12.5 feet above the beam line. There are no photo tubes mounted above the location. The nearest photo tubes are 2 to 3 feet to the north and west of the location. The likelihood of such a leak is say 25 items * (3E-6 failures/ $\mathrm{hr})(8766 \mathrm{hrs} / \mathrm{yr})=0.7$ leaks per year. The total leak rate would be a maximum of 1 $\mathrm{cc} / \mathrm{sec}$ air $=0.005 \mathrm{scfm}$ helium. (Note that a leak detectable by snoop is $1 / 1000^{\text {th }}$ of this $=0.001 \mathrm{~atm}-$

\footnotetext{
${ }^{2}$ Incropera and Dewitt. Fundamentals of heat and mass transfer, $2^{\text {nd }}$ ed., 1985.
} 
$\mathrm{cc} / \mathrm{sec}$ air). For the sake of a number, assume the helium is distributed through a spherical volume with 3 foot radius. The resultant helium background would be around $180 \mathrm{ppm}$. The concentration level should reduce as cubic function of the distance from the source. The duration of such a release could be for the whole run since the leak may not he noticed or discovered. Even though the probability is that one such leak would occur every year and a half, the total leak rate assumed is rather large and should account for any combination of multiple leaks that may occur during the run.

\section{0 ppm Helium}

[Away from tubes]

2. Lead flow returns from solenoid: The method and location of a leak from these items is similar to the solenoid supply lines above. The elevation of such a leak is a few feet higher, within 5 feet of the top of the detector. There are going to be 6 potential leak sites all enclosed in the lead flow purge box. The GN2 purge box would dilute any such leak by about $0.5 \mathrm{scfm}$ purge $/ 0.005 \mathrm{scfm}$ helium $=100$ before it's release out of the box. The elevated helium concentrations are 100 times less than those calculated for source number 1 . That is ( $5 \mathrm{ppm}$ (natural background) $+6 \mathrm{ppm}=) 11 \mathrm{ppm}$ at 2 feet away and ( 5 ppm (natural background) $+2 \mathrm{ppm} \Rightarrow) 7 \mathrm{ppm}$ at 3 feet away.

Negligible ppm [Away from tubes]

3. Relief valves from solenoid control dewar: The solenoid has relief valves that protect the process lines and helium subcooler vessel. The cause of a relief discharge could be a quench or an operational upset. The location of the discharge and elevated helium atmosphere is the control dewar location described in the previous cases. It's hard to estimate how often a release could happen, in the operational test of the magnet at Toshiba the relief valves did not come close to having to open from a forced quench of the magnet. For a rough guess, say it might occur 4 times a year. The rate of release is large $616 \mathrm{cfm}$ helium, for a short duration, say 5 seconds at most, for a release of about $50 \mathrm{scf}$ helium (equivalent to 2 liquid liters of helium). The local concentration would initially he high, approximately $100 \%$ up to 3 feet from the relief valve. Modeling the helium as a sphere, the sphere would rise above and away from the detector in a matter of seconds. Any such releases from the relief valves would be discrete short term exposures of helium to the tuhes.

\section{$100 \%$ Helium $<1 \mathrm{~min}$. [Away from tubes]}

4. Liquid helium supply/returns for VLPC detector. These lines connect via u-tubes in the same area as the solenoid control dewar. There are 6 bayonets and 6 trapped volume relief vaives at that Jocation. The conservative failure rate of the bayonets and relief valves is about 0.3 failures per year. A leak rate of $0.005 \mathrm{scim}$ helium is reasonable. The duration of such a leak would probably he for the duration of the run. The maximum local concentration at the end of 5 years above the bayonet feed can could be $(5 \mathrm{yrs})(0.3 / \mathrm{yr})(180 \mathrm{ppm})=270 \mathrm{ppm}$. This location is not in the area of any photo tubes.

\section{0 ppm Helium}

[Away from tubes]

The other leak sources are the stems of two control valves iocated in a valve box in the center-east section of the detector platform. These stems are beilow sealed and each have a failure rate of about $(\mathrm{IE}-8 / \mathrm{hr})^{*}(8677 \mathrm{hrs} / \mathrm{yr})=1.7 \mathrm{E}-4$ per year. The valve box location is probably within 10 feet of a "B" or "C" layer photo tube. The failure rate is low enough that it can be neglected. If it did fail, the mixing and distances involved would probably cause a maximum helium concentration of about $80 \mathrm{ppm}$ at the closest photo tube Iocation. The helium concentration would probably dilute by the distance from the 
source cubed. So photo tubes 20 feet away would see at most $10 \mathrm{ppm}$ above the normal atmospheric concentration.

10 ppm Helium
$[4$ to 6 "B,C" layer tubes]

5. Cassette space gas helium volume: The cassette space volume is located in the center of the detector platform. The cassette space is a stagnant volume that surrounds the cold end of each of the 102 VLPC cassettes. Each VLPC cassette has a gasket and silicone potting at the warm optical fiber/flex circuit bulkhead. I'll estimate the leak rate for a cassette bulkhead to be $1 \mathrm{E}-2 \mathrm{~atm}-\mathrm{cc} / \mathrm{sec}$ helium $=2 \mathrm{E}-5 \mathrm{cfm}$ helium. Multiplied by the 100 cassettes, then the total steady state leak rate is going to he $0.002 \mathrm{cfm}$ distributed over the $1.5 \mathrm{ft} \times 12 \mathrm{ft}$ long surface area of the cryostats. The center section of the platform is ventilated with fans at a rate of $2080 \mathrm{cfm}$ and has a volume of about $1600 \mathrm{cf}$. The raised helium concentration from the cassette leaks is on the order of 1 or $2 \mathrm{ppm}$.

Negligible ppm

[By 10 to 20 "B" layer tubes]

There-are going to be low pressure relief yal ves protecting the cassette space. These will relieve pressure generated from a warm up of the cassette space. These relief valves are going to have their outlets piped into the argon spill duct which is located not more than 10 feet away. The spill duct has continuous ventilation out of the detector area.

A cassette change operation would al so release helium gas. A cassette change would occur 2 times per year at most. Operational spares are included as a subset of the total 102 cassette installation. During a change out one probably would keep a positive helium supply to the cassette space to prevent back streaming of air and moisture into the cassette space which could be cold. In hetween the actual removal of the cassette and blanking off the hole again, helium would escape out of the cassette slot for 1 to 2 minutes. I estimate $30 \mathrm{scf}$ of helium is released during this operation. The elevated helium background in the center section of the platform could be as high as $1.25 \%=12.500 \mathrm{ppm}$ helium for a couple of minutes. The concentration would then decrease exponentially thereafter.

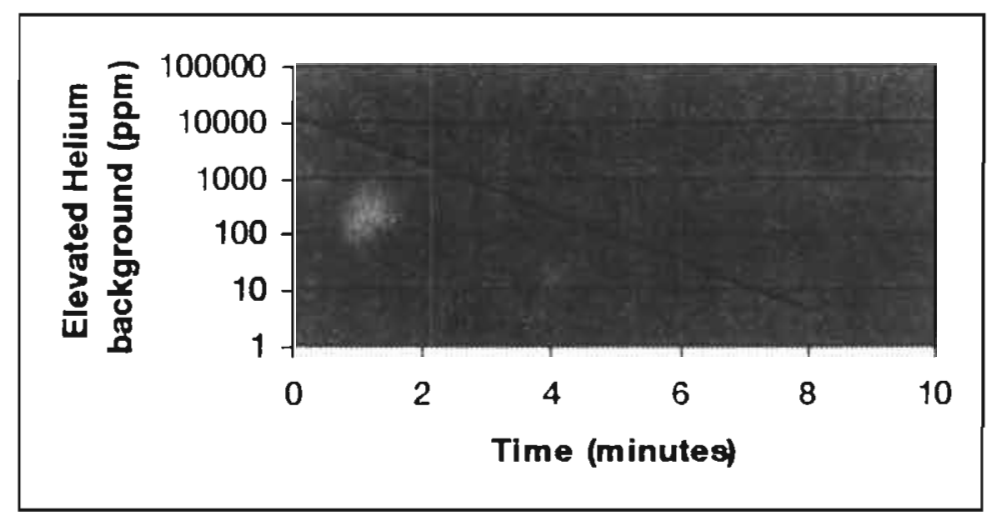

$1.3 \%$ He decaying to $<100 \mathrm{ppm}$ in $5 \mathrm{~min}$.

[By 10 to 20 "B" layer tubes]

6. Calorimeter cold valve actuation gas: The cold valves are fed by $1 / 4$ " tubing lines that run from the cryo comer area (SE comer of platform) up the cryobridge and to the tops of the three calorimeters. The tubing for the most part is continuous with some joints. There are muon chambers and counters within a few feet of the tubing run. The probability of a leak is around (10 joints)(1E-8/hr)(8766 
$h r / y r)=0.00087$ per year or about 1 in a 1000 odds. The maximum leak that could reasonably occur is around $0.005 \mathrm{sctm}$. This leak could cause an elevated helium atmosphere of $500 \mathrm{ppm}$ at the closest photo tuhe should a leak occur. Another release is due to the actuation of the cold valve. The solenoid that applies helium to the cold valve releases a slight burp when energized. The manufacturer says there is a slight leakage, so I'll interpret that to be $1 \%$ of the full flow $\mathrm{Cv}=0.09$ (orifice of $1 / 16^{\prime \prime}$ ). The equivalent leak rate is $0.9 \mathrm{cfm}$. This is a momentary 5 second puff that could cause a local atmosphere of $7 \%$ helium within a foot of the solenoid. This would rapidly dilute away due to the density difference between the helium and air regardless of whether there was a trapped pocket above the location or not.

\section{$7 \%$ He decaying to $<100 \mathrm{ppm}$ in 30 minutes \\ [By 2 "A" layer tubes]}

7. Tevatron magnets and the tunnel: This is a hard source to quantify. The components are located on the north and south ends of the collision hall and would impact the outer most layer of counters on the north and south faces of the detector. The magnets and tunnel probably would have a steady state leak rate and probability not too different from the solenoid control dewar components, sources 1 through 4. The ODH anaiysis (conservative) lists a maximum leak rate from a powered low beta quad magnet at $1898 \mathrm{scfm}$. The probability of such a failure is $2 \mathrm{E}-6 / \mathrm{hr}=1$ in 60 chance per year (also conservative). The circulating ventilation rate (non fresh make-up) for the collision hall is $24,000 \mathrm{cfm}$ and the volume of the collision hall is about $100,000 \mathrm{cf}$. Just to get a number, assume the failure occurs and the release last $s$ for 3 minutes. In that time, about $5700 \mathrm{cf}$ of helium would be released into $100,000 \mathrm{cf}$ of air. The helium concentration could be as high as 5 to $7 \%$ initially. The gas helium would escape out the top of the collision hall, and the large ODH ventilation fans would be kicked on mixing and diluting the concentration from there. The ventilation rate during such an event would be at least $1 / 4$ volume change per minute.

\section{$5 \%$ He decaying to $<100 \mathrm{ppm}$ in 25 minutes.}

[Magnet rupture, Envelopes D0 detector]

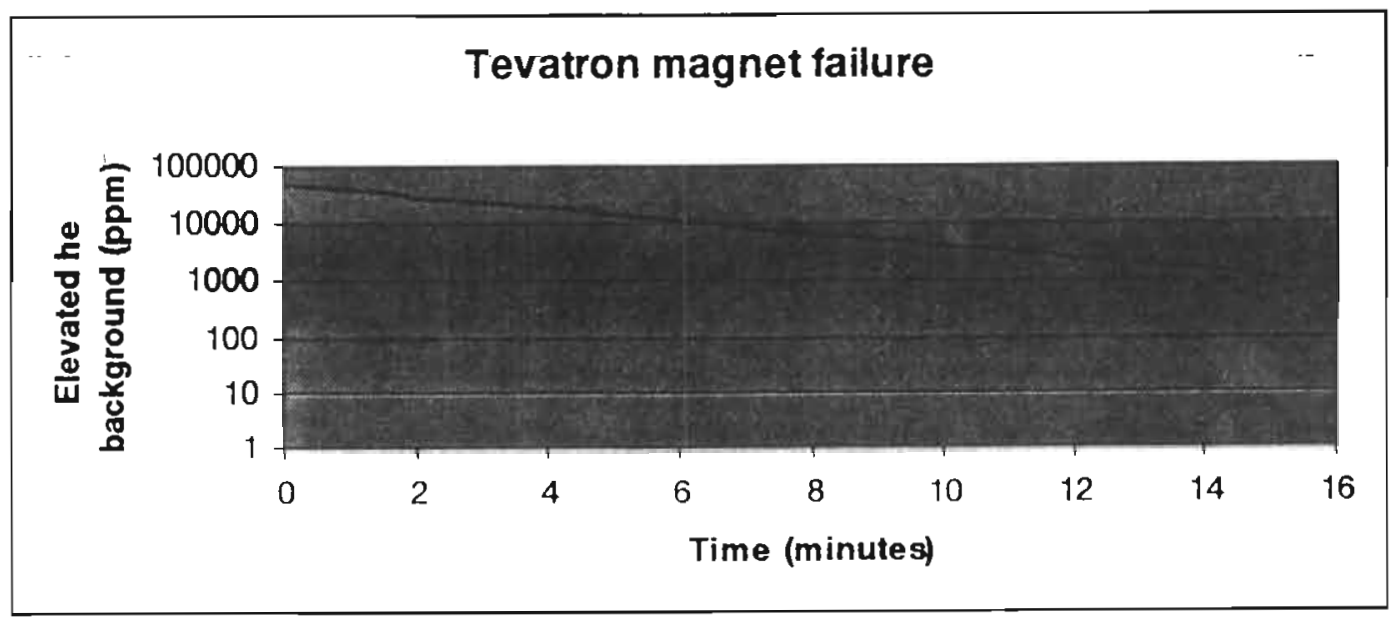




\title{
APPENDIX
}

\author{
HELIUM BACKGROUND IN THE D-ZERO DETECTOR \\ RELATED TO LUMINOSITY DETECTORS \\ UNI-DIRECTIONAL DISPERSION METHOD
}

D-ZERO ENGINEERING NOTE \# 3823.130-EN-490

Approved:

Kun Krempetz, PPD/ETT/DO Upgrade/Mechanical group leader

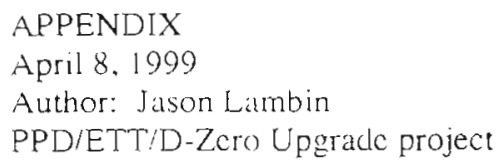




\section{Purpose and Background}

The purpose of this addendum is to provide an alternative helium dispersion theory to that which is presented in D-Zero Engineering Note \# 3823.130-EN-490. The following theory assumes that helium travels from each source radially in all directions, resulting in a sphere of air containing an elevated level of helium. Each sphere's radius corresponds to the distance from the source of the helium leak to the nearest photomultiplier tube location. These distances were determined via fabrication prints and field measurements.

\section{Dispersion Behavior}

The following diagram illustrates the basic premise of this theory.

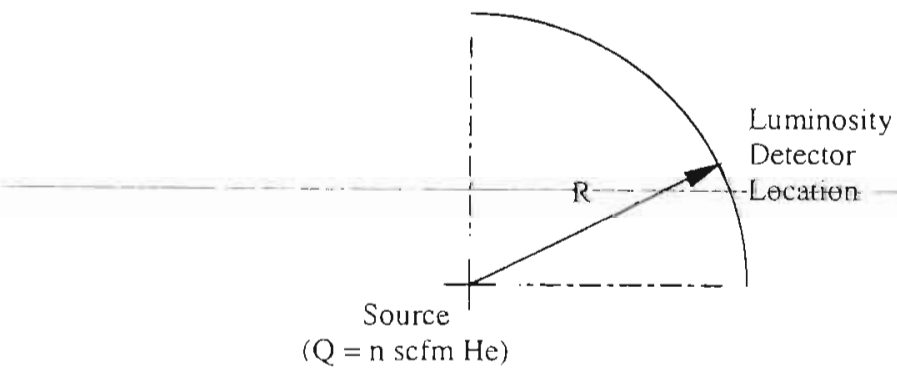

This theory assumes that the sphere of elevated helium in air is exchanged with fresh air at a rate of one quarter of its volume per minute. A volumetric flow rate for fresh air can be obtained using the following relation:

$$
(4 \Pi / 3) * \mathrm{R}^{3}[\mathrm{cf}] * 1 / 4[\text { minutes }]=\Pi^{*} \mathrm{R}^{3 / 3}[\text { scfm fresh air }] .
$$

Two different equations are used to determine the increase in helium content, based on whether the leak source is continuous or discrete. For a continuous leak, the equation is as follows:

$$
\mathrm{x}[\mathrm{ppmHe}]=\mathrm{n}[\operatorname{scfm~He}] /\left(\Pi^{*} \mathrm{R}^{3} / 3\right)[\operatorname{scfm} \text { fresh air }] * 10^{6} \text { [parts per million] }
$$

For a discrete leak, the initial elevated helium concentration can be calculated according to the following:

$$
\mathrm{x}[\mathrm{ppm} \mathrm{He} \text { mitial }]=\mathrm{n}[\mathrm{sctm} \mathrm{He}]^{*} \mathrm{t}[\text { minutes }] /\left((4 \Pi / 3)^{*} \mathrm{R}^{3}\right)\left[\mathrm{cf} \text { gas mix }{ }^{*} 10^{6}\right. \text { [parts per million] }
$$

where $t$ is the duration of the leak. The attached table shows the results obtained using this model. 

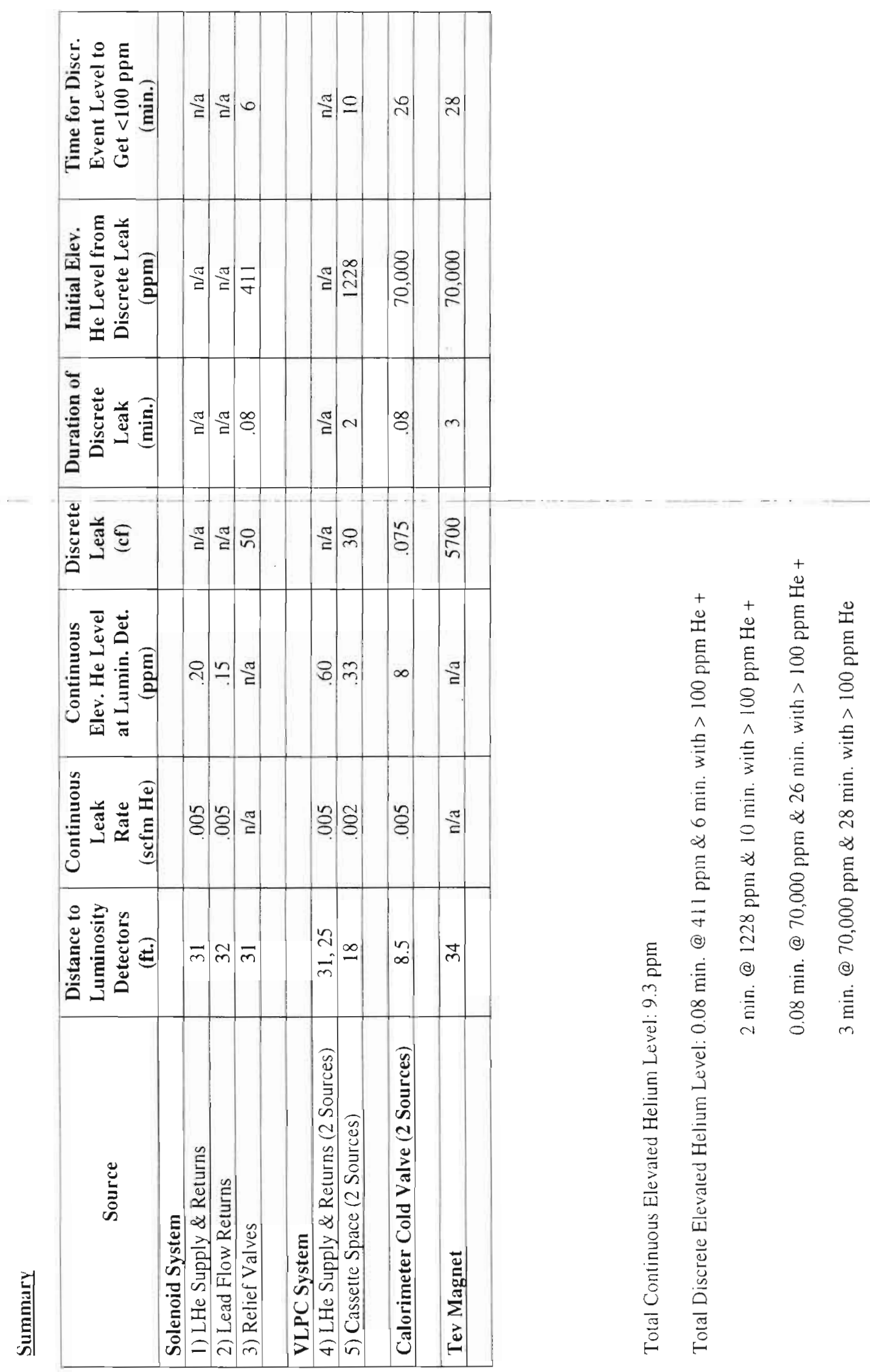
Jason Laminin

$2 / 199$

Determination OF Quantities In The Table Titleo,

"Helium Background In Detector Recative To Photomultipller TUEES

2.) Lgad Flow Returens

- Distance- Same As ij But More Elguation

$$
x=20^{\prime}, y=18^{\prime}, z=17^{\circ} \Rightarrow \text { DIST. }=32^{\prime}
$$

- Conpinuars - Assume. DOS SCfm ceak

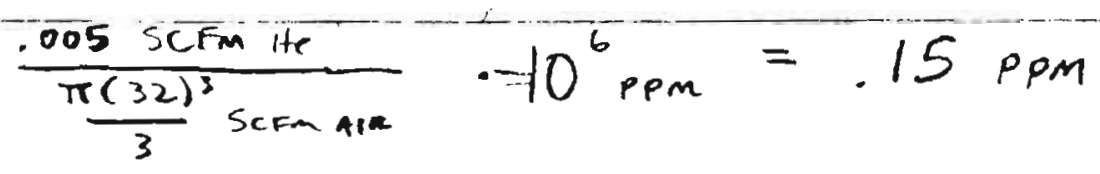

3) RELIEF VALVES

- Distance - Same ts i), 31.

- Discrete- 616 SCFM for 5 secondos $\Rightarrow 50$ scF He LEAK QuRation $=5 / 60=.083$ MINUTES

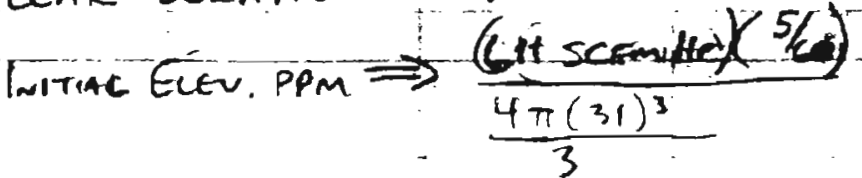

$10^{6}=$

Time $T_{0} G_{E T}<100 \mathrm{ppm} \Rightarrow 4$ ili pom livi fracly

$$
C_{e}(t)=1=\left[1-C_{R}\left(t_{e}\right)\right] e^{\left[\left[a\left(t-t_{c}\right) / v\right]\right.}
$$

From FCami ES +H

$Q=V$ ENT. RATE OF FANS $=1 / 4 V=1 / 4(124 ; 718)=31200$ $V=$ Confinta Vount Or He $=4 \pi\left(31^{3}\right) / 3=124,788 \mathrm{CF}$. $5064-7 A-8$
$\operatorname{Ean}(8)$ $t-t_{E}=$ Tme AETER Gino Or RELEASE

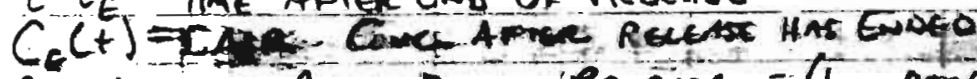
$C_{R}(t)=$ AIR ConNe Duewe RECEASE $=(1-.000411)$

- L Hate Founo V To Be > 100,000 CF THe Detector's Vocume. The means TiHe Hecium Woulo Engule THe Detector as a Result Of The Type of leak. THUS, 1 Wiu USE $V=100,000 \mathrm{CF}+Q=24,000 \mathrm{CFM}$ (Max. Ventication rate).

$$
C_{E}(t)=1-[1+(1+.000411)] e^{\left[-24,000\left(t-t_{E}\right) / 100,000\right]}
$$

Iterate Thes Untic $C_{E}(t)=.999900$ (<100 Ppm He) - find What Corresponanc $t-t_{\epsilon}$ is

$$
\therefore t-t_{E}=6 \text { MwUTES }
$$


4) VLPC Lie Super or Returns

2 Sourcelochion: Bayonets + Relief Values, 2 Control Values

- bayonets o Relief i - $(5$ yrs $)(.3$ alludes $/$ yr) $(2 \mathrm{im})=.3 \mathrm{pPm}$

- 2 Control Valves - Continuous -

Assume, 005 SCFM He

D stance : $x=18^{\prime} \quad y=18^{\prime} \quad z=0 \quad \therefore$ DIST. $=25^{\prime}$

$\frac{.005 \text { SCAm He }}{\frac{\pi}{3}\left(25^{\prime}\right)^{3} \text { SCI ARR }} \cdot 10^{6} \Rightarrow .30 \mathrm{PPM}$

Total He LeAK From i) $\rightarrow \quad .60$ pPM

5) Cassette Sane Gas Volume

2 Tres OF LEaK: Continuous Fred GaskeT

Discrete from Cassette Change

- Continuous -

Assume .002 SCFM He

Distance: $x=5^{\prime} y=17^{\prime} \quad z=0 \quad \therefore$ Dist $=18^{\prime}$

$$
\frac{.002 \mathrm{scFm} \mathrm{He}}{\frac{\pi}{3}\left(18^{\prime}\right)^{3} \mathrm{sermAlR}} \cdot 10^{6} \Rightarrow .33 \mathrm{pPM}
$$

- Discrete -

Escape time: $1 \rightarrow 2$ minutes yielding to $30 \mathrm{schi}$ He Recessed

$$
\text { -. } \frac{(30 \mathrm{SCF} H e)}{\frac{4}{3} \pi\left(8^{\prime}\right)^{3} \text { SCH AIR }} \cdot 10^{6}=1228 \mathrm{PPM}
$$

Us

$$
\begin{gathered}
C_{\epsilon}(t)=1-\left[1-C_{R}\left(t_{E}\right)\right] e^{\left[-Q\left(t-t_{t}\right) / v\right]} \\
Q=\frac{1}{4} V=400 \mathrm{cFm} V=[600 \mathrm{CF} \\
C_{\epsilon}(f)=1-[.001228] e^{\left[-.400\left(t-t_{\epsilon}\right) / 1600\right]}
\end{gathered}
$$

$t-t_{E} \approx$ To minutes.

Again...

iterate +... 
6) Calorimeter Colo Valve actuation gas

2 Sources: Joint: In Thong, Cold Valve Actuation - Joints in tubing - Continuous .005 JCFM HE LEAK

Distance $=x=0$ $y=8.5^{\circ}$ $z=0$

$\frac{.005 \text { SCFM He }}{\frac{\pi}{3}\left(8.5^{\prime}\right)^{3}} \cdot 10^{6}=8$ PPM

- Cold Valve - Discrete -

9 SCFM For 5 SECONDS $\rightarrow 7 \% \mathrm{He}_{e}=.07$

$C_{6}(t)=1-\left[1-C_{R}\left(t_{E}\right)\right] e^{\left[-Q\left(t-t_{e}\right) / N\right]}$

$$
\begin{aligned}
& V=\frac{\pi}{3}\left(8.5^{\prime}\right)^{3}=2-C F \\
& Q=1 / 4 V=643 \mathrm{CFM}
\end{aligned}
$$

$$
G_{E}(t)=1-[.07] e^{\left[-643\left(t-t_{t}\right) / 2572\right]}
$$

$$
\therefore t-t_{\epsilon}=26 \text { minutes }
$$

7) Teuatron Magnets a Tunnel

I Discrete -

LiTERaTE THE..+

- Elevated He As High as Ti tivitincey

$$
C_{E}(t)=1-\left[1-C_{R}\left(t_{E}\right)\right] e^{\left[-Q\left(t-t_{E}\right) / V\right]}
$$

$Q=-1 / 4 V, F_{D} V$

Distance: Monsureo Distance From Assembly tare South Ware to Cryo Bride $\approx 26^{\prime \prime}$

Distance From Cryobrivge to tues $\approx \overline{8}^{\prime}$

Thus. Tatar Distance $=34$

$$
\begin{aligned}
& V=\frac{4 \pi}{-3^{1}}(34)^{3}=1546.36 \text { CF USE V }=100,000 \mathrm{CF} \\
& Q=41.160 \text { cum }+ \text { USE } Q=24,000 \mathrm{cFm}
\end{aligned}
$$




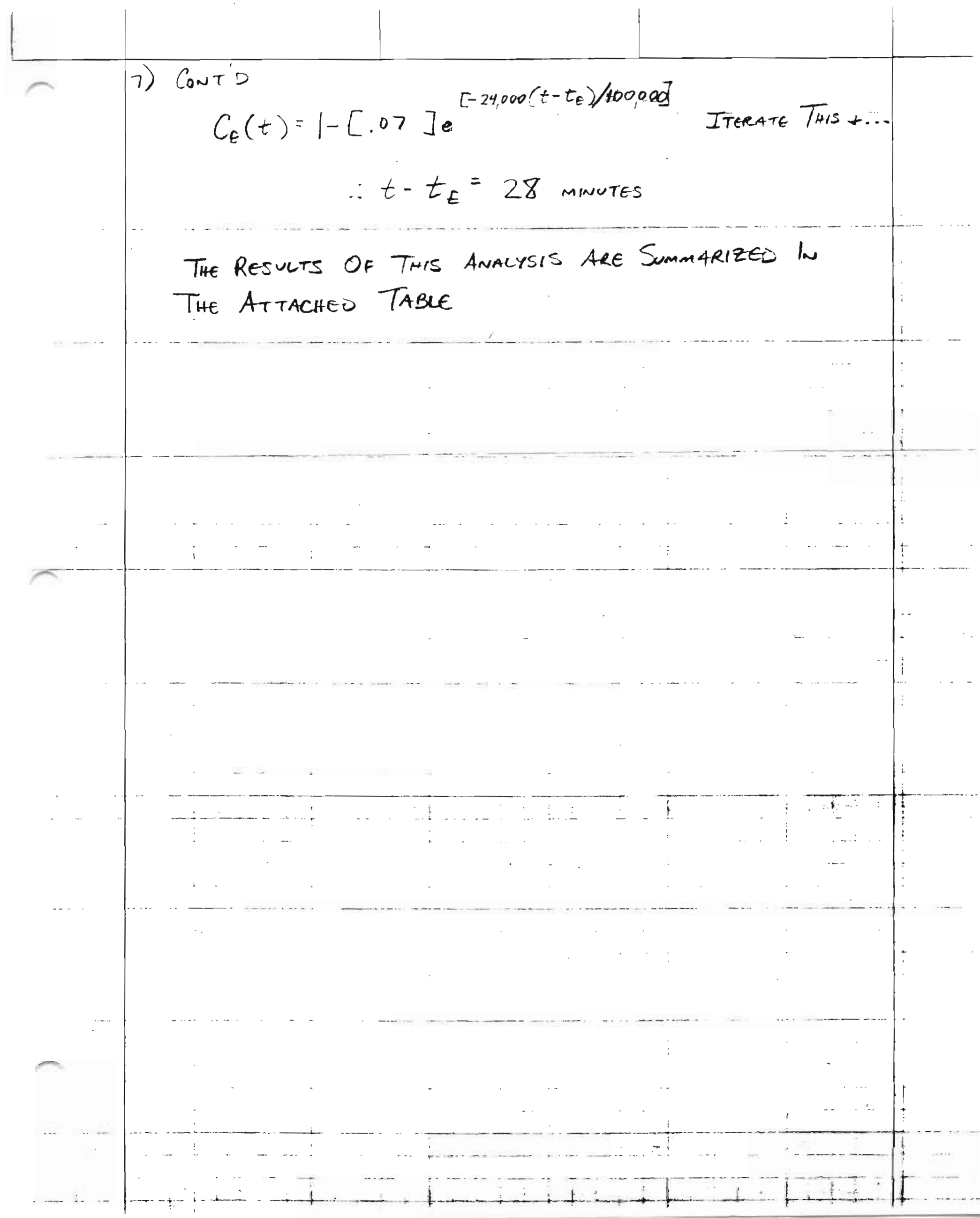


1

ing

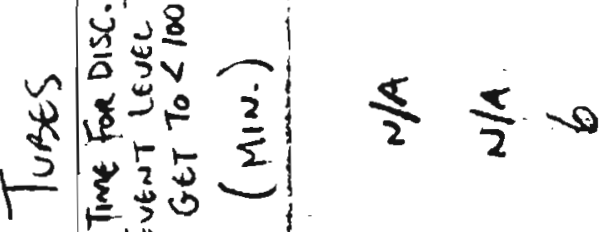

$\frac{\pi}{2} \stackrel{0}{-}$

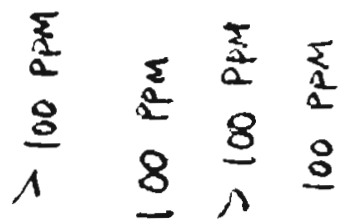

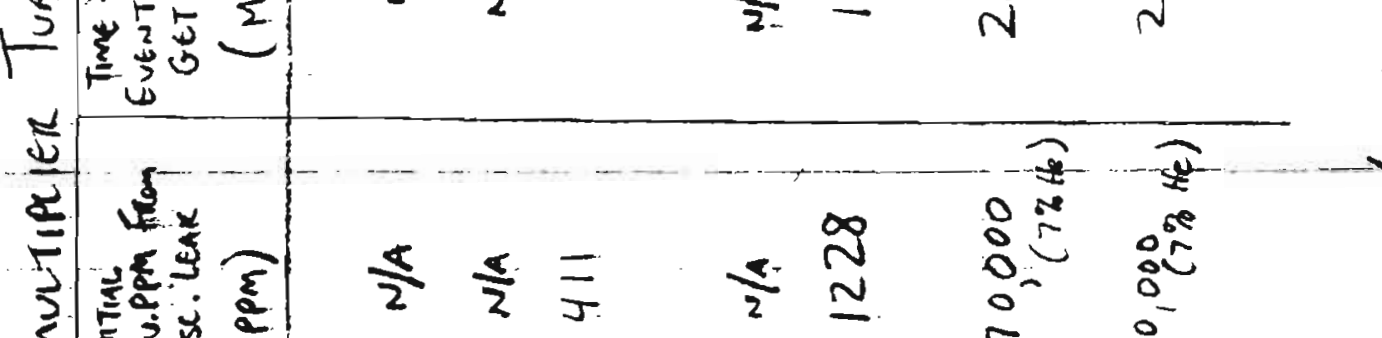

:

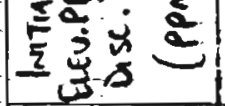

$\frac{x}{2} \frac{x}{2} \bar{y}$

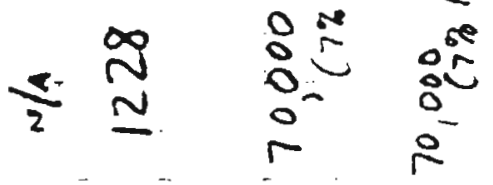

위는

ร 악

치

$\geqslant \wedge$ 싯

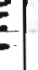

z

10

(t)

i

$\frac{\pi}{2} \frac{2}{2}: \infty$

졸

$m$

$\$ 2 \frac{1}{0}$

5

$\left(\begin{array}{ll}5 \\ 5 \\ 3 \\ 4\end{array}\right.$

$\approx$

x心

J

岀|

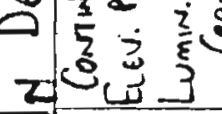

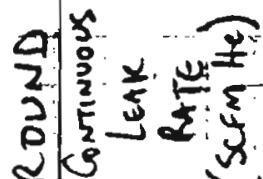

$y$

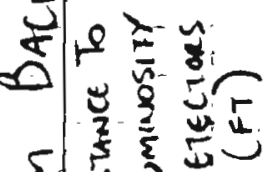

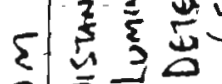

立
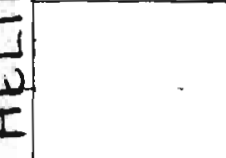

$-\frac{2}{3}$

$\stackrel{0}{N} \frac{\pi}{2}$

$0_{0}^{1} m$

$\infty$

$\frac{n}{2} \quad \frac{8}{r}$

$\begin{array}{llllllll}n & n & n & 1 & 0 & 0 \\ 0 & 0 & \frac{1}{2} & 0 & 0 & 0 & 0\end{array}$

$\frac{5}{2}$

赛

产

\& $\frac{8}{2}$

(3) 전

-

(a)

$\frac{2}{2} 00$

$\begin{array}{cccc}\infty & \frac{z}{\Sigma} & \bar{\Sigma} & \frac{2}{\Sigma} \\ 0 & N & 0 & n\end{array}$

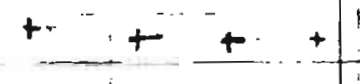




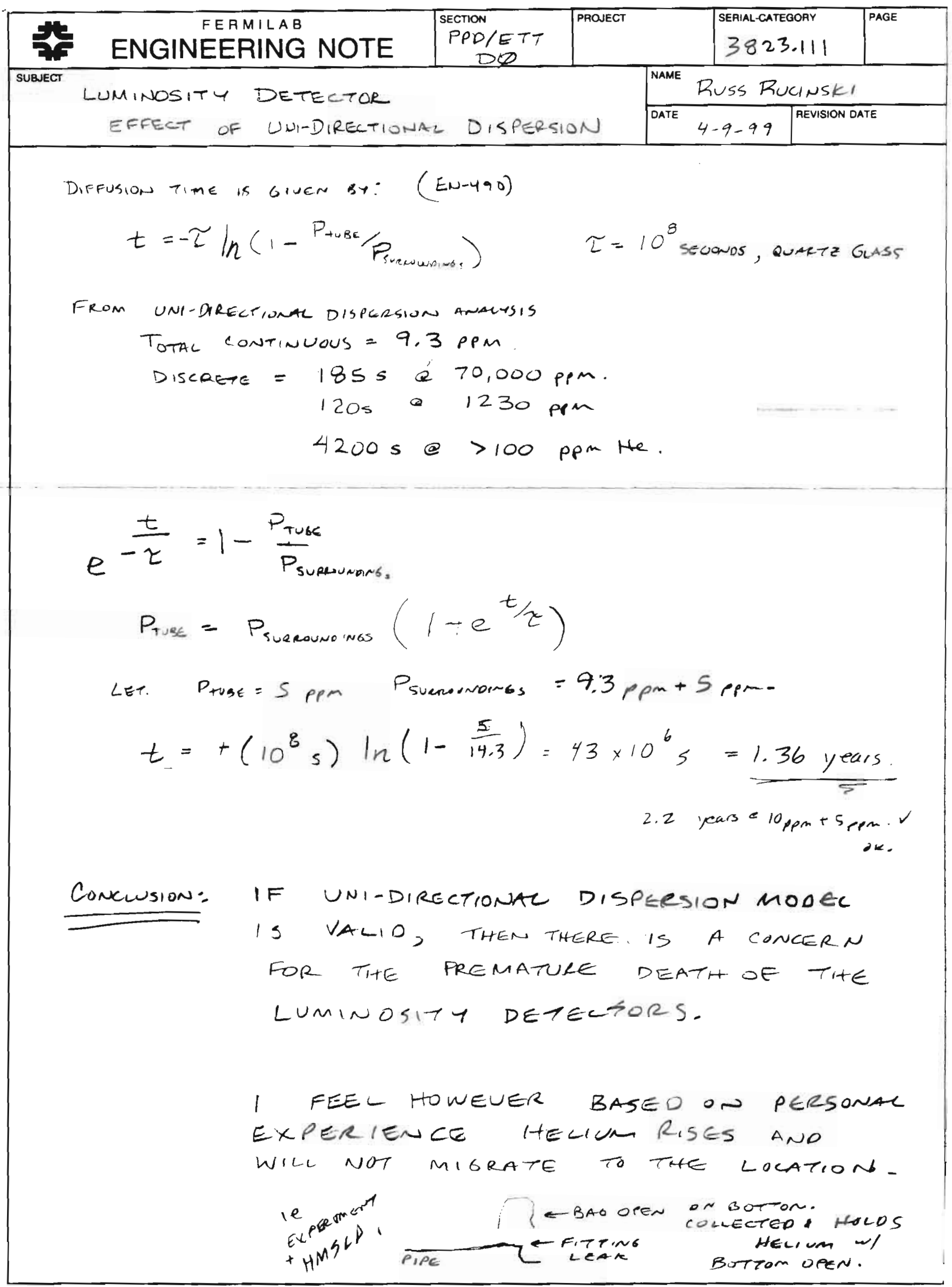




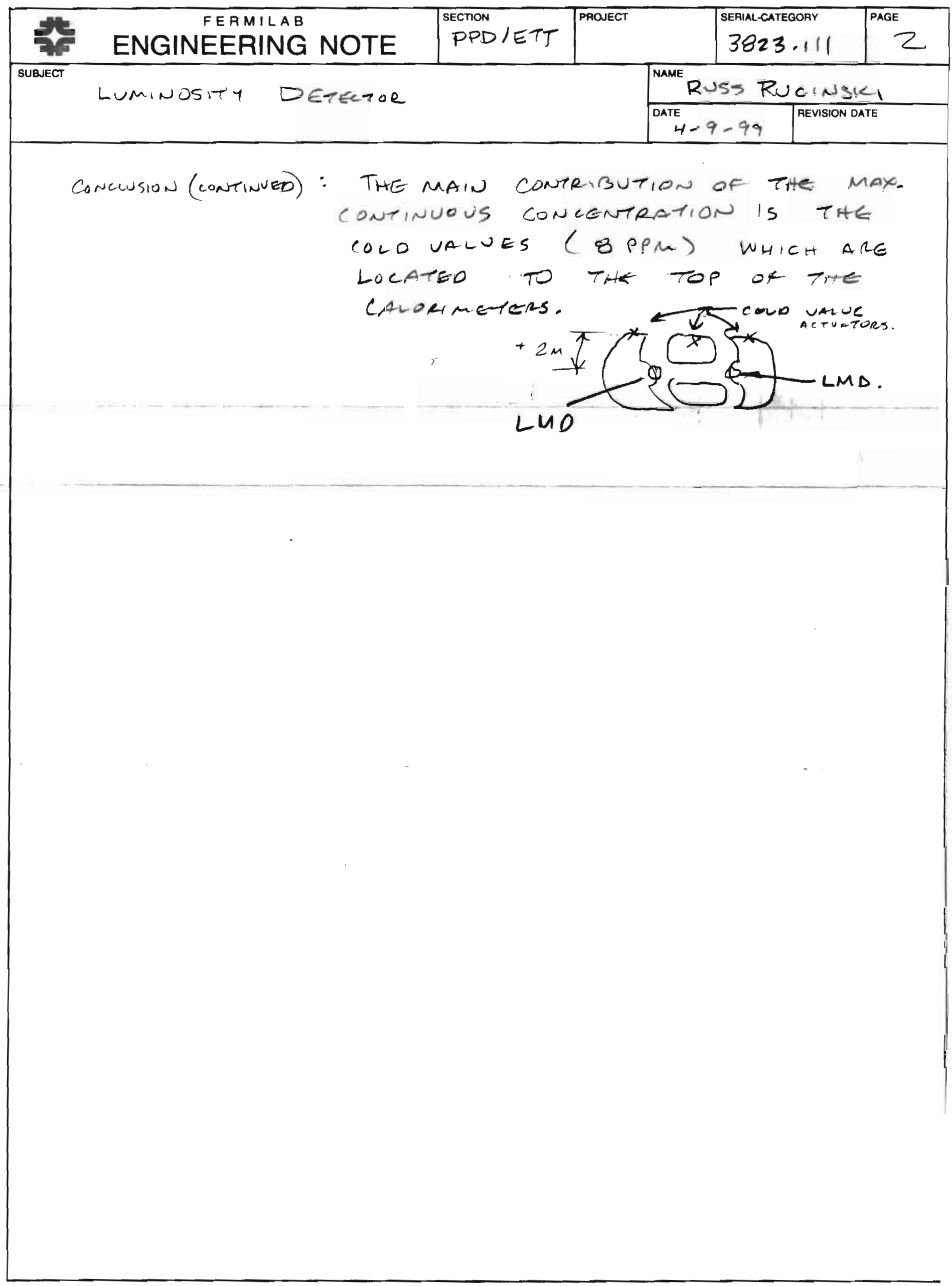

